\title{
Association between optic disc haemorrhages in glaucoma and abnormal glucose tolerance
}

\author{
D POINOOSAWMY, J GLOSTER, S NAGASUBRAMANIAN, AND \\ R A HITCHINGS
}

From the Glaucoma Unit, Moorfields Eye Hospital, High Holborn, London WC1

\begin{abstract}
SUMMARY Data concerning the results of glucose tolerance tests and levels of intraocular pressure were analysed for 120 patients with primary open-angle glaucoma, many of whom had been under observation for a period of four to five years. The patients consisted of two groups: in 62 patients a disc haemorrhage had been recorded at some time during the observation period, and in 58 no haemorrhages had been seen. Patients with disc haemorrhages had a higher incidence of abnormal glucose tolerance or frank diabetes and lower intraocular pressures than those without haemorrhages.
\end{abstract}

Evidence of an association between diabetes mellitus and glaucoma has existed for more than 20 years, and in 1971 Becker' presented a review of previous work combined with his own investigations from which he drew the clinical implications that glaucoma should be suspected in diabetics, and that diabetes should be suspected in patients with primary open-angle glaucoma, especially those with low tension glaucoma. The present investigation was undertaken to examine the association between glaucoma and diabetes with particular reference to the occurrence of haemorrhages on the optic disc.

It has recently been pointed out ${ }^{2}$ that Bjerrum described haemorrhages on the optic disc in glaucoma almost 100 years ago, but thereafter little attention seems to have been paid to this observation until Drance and Begg ${ }^{3}$ published their description. It has now been established that disc haemorrhages occur in at least one-third of patients with open-angle glacoma,$^{45}$ that they may be observed in the early stages of the disease,${ }^{6}$ and that they are related to the progression of visual field loss.' Although the precise relationship of these haemorrhages to the pathology of the glaucomatous optic nerve head is still not clear, it was considered that our present knowledge of changes in small blood vessels in diabetes mellitus indicated a need to make a special retrospective study of a possible association between abnormal glucose tolerance and glaucomatous disc haemorrhages.

Correspondence to Mr R A Hitchings, Glaucoma Unit, Moorfields Eye Hospital, High Holborn, London WC1A 7AN.
Some subsidiary observations were made of systemic blood pressure and of the location of disc haemorrhages.

\section{Patients and methods}

The investigation involved two groups of patients with established primary open-angle glaucoma, manifested by glaucomatous cupping of the optic disc and characteristic field defects. The first group consisted of 62 patients in whom a disc haemorrhage had been observed at some time during routine followup. The second group consisted of 58 patients who were examined at approximately the same time as those in the first group but in whom a disc haemorrhage had never been observed. They were selected from the general run of glaucoma follow-up patients only in so far as an attempt was made to make the groups comparable as regards age and sex composition. Most of the patients had been seen in the glaucoma clinic at intervals of 3-6 months for an average period of 4-5 years. All patients had had complete ocular examinations, including examinations of visual acuity, intraocular pressure, visual fields, and fundus, together with disc photography, measurement of systemic blood pressure, and recording of pulse rate. In addition they all had random blood sugar estimations and those who had random blood sugar levels greater than $5 \mathrm{mmol} / \mathrm{l}$ were subjected to a standard glucose tolerance test. This involved fasting from midnight and stopping all 
medication for 48 hours, but without restriction of water, until arrival in the clinic on the following morning. At this time the visual acuity, intraocular pressure, systemic blood pressure, and pulse rate were recorded, and a sample of venous blood was collected. Patients were then given $75 \mathrm{~g}$ of glucose dissolved in $200 \mathrm{ml}$ of water flavoured with lemon or orange to drink over a short period of time. A sample of blood at 30-minute intervals was collected over two hours. All blood samples were sent to the Pathology Department of the Institute of Ophthalmology for estimation of plasma glucose levels. The intraocular pressure, blood pressure, and pulse rate were also recorded at 30-minute intervals during the test.

\section{Results}

Table 1 shows that there was no significant difference between the two groups of patients as regards age and sex distribution. Table 2 shows maximum pretreatment intraocular pressures recorded at any stage, random blood sugar levels, and systemic blood pressures in the two groups. There was no significant difference between the groups as regards systemic blood pressure, but 15 patients with disc haemorrhages and six without had diastolic pressures of 110 mmHg or above.

There were significant differences between the two groups as regards random blood sugar levels and maximum recorded intraocular pressures. These results are shown graphically in Fig. 1, from which it can be seen that patients with disc haemorrhages tended to have higer blood sugar levels and lower intraocular pressures than those without haemorrhages $(\mathrm{p}<0 \cdot 05)$.

The results of glucose tolerance tests (GTT) are shown in Table 3. The GTT results have been divided

Table 1 Age and sex distribution of patients

\begin{tabular}{lcccl}
\hline Patients & No. & Male & Female & $\begin{array}{l}\text { Age, mean } \\
\text { SD (range) }\end{array}$ \\
\hline With disc haemorrhage & 62 & 28 & 34 & $\begin{array}{l}68 \cdot 4 \pm 20 \cdot 9 \\
(44-88)\end{array}$ \\
Without disc haemorrhage 58 & 28 & 30 & $\begin{array}{l}67 \cdot 8 \pm 20 \cdot 86 \\
(51-38)\end{array}$ \\
\hline
\end{tabular}

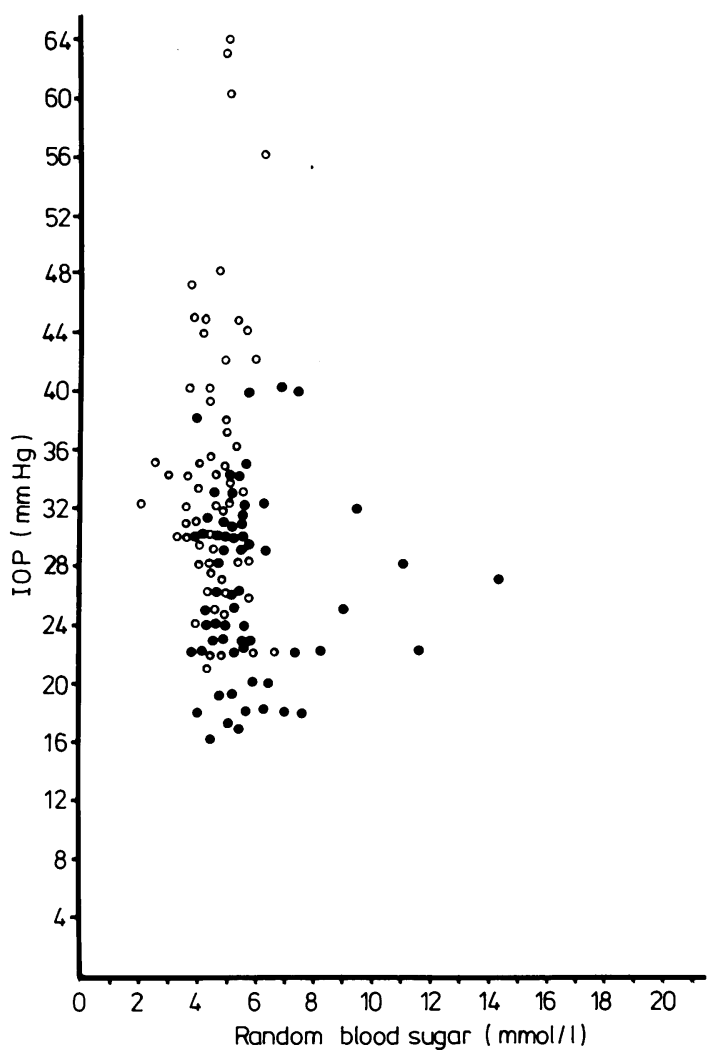

Fig. 1 Random blood sugar levels and maximum recorded intraocular pressures in the two groups of patients.

$\mathrm{O}=$ Without disc haemorrhage. $\mathrm{O}=$ With disc haemorrhage.

as normal, impaired, or diabetic, according to the criteria laid down by the World Health Organisation Expert Committee on Diabetes Mellitus. ${ }^{8}$ The higher incidence of impaired and diabetic GTT results in patients with disc haemorrhages was significant $\left(\chi^{2}=\right.$ $8 \cdot 8, p<0 \cdot 01)$. These results are presented in greater detail in Fig. 2.

The topographical distribution of the observed disc haemorrhages is shown in Fig. 3, indicating that $50 \%$ of haemorrhages occurred in the lower half of the disc between 5 and 7 o'clock, especially in the inferotemporal region. The mean maximum recorded intraocular pressure in patients showing haemor-

Table 2 IOP, blood glucose, and systemic BP in the two groups of patients

\begin{tabular}{|c|c|c|c|c|c|}
\hline \multirow[t]{2}{*}{ Patients } & \multirow[t]{2}{*}{ No. } & \multirow{2}{*}{$\begin{array}{l}\text { Maximum IOP, mean } \pm S D \\
(\mathrm{mmHg})\end{array}$} & \multirow{2}{*}{$\begin{array}{l}\text { Random blood glucose, } \\
\text { mean } \pm S D(\text { mmolll })\end{array}$} & \multicolumn{2}{|c|}{ Blood pressure, mean $\pm S D(m m H g$} \\
\hline & & & & Diastolic & Systolic \\
\hline $\begin{array}{l}\text { With disc haemorrhage } \\
\text { Without disc haemorrhage }\end{array}$ & $\begin{array}{l}62 \\
58\end{array}$ & $\begin{array}{l}26 \cdot 3 \pm 6 \cdot 13 \\
34 \cdot 7 \pm 10 \cdot 51\end{array}$ & $\begin{array}{l}5 \cdot 94 \pm 1.90 \\
4.69+0.79\end{array}$ & $97 \pm 12 \cdot 6$ & $161 \pm 20 \cdot 6$ \\
\hline
\end{tabular}


Table 3 Incidence of impaired glucose tolerance and diabetes in the two groups of patients

\begin{tabular}{|c|c|c|c|c|}
\hline Patients & No. & $\begin{array}{l}\text { Percentage with normal } \\
\text { glucose tolerance }\end{array}$ & $\begin{array}{l}\text { Percentage with impaired } \\
\text { glucose tolerance }\end{array}$ & Percentage diabetic \\
\hline With disc haemorrhage & 48 & $52 \cdot 1$ & $33 \cdot 3$ & $14 \cdot 6$ \\
\hline Without disc haemorrhage & 32 & $84 \cdot 4$ & $9 \cdot 4$ & $6 \cdot 3$ \\
\hline
\end{tabular}

rhages in the horizontal (that is, nasal and temporal) sectors of the disc was $29.88 \mathrm{mmHg}(\mathrm{SD}+12 \cdot 46)$, as compared with $23.20 \mathrm{mmHg}(\mathrm{SD}=6 \cdot 55)$ for patients with haemorrhages in the vertical (that is, upper and lower) sectors of the disc; this difference was significant $(\mathrm{p}=0 \cdot 005)$.

\section{Discussion}

Our study has shown two differences between glaucoma patients with disc haemorrhages and those without. The first difference was that almost $50 \%$ of patients with haemorrhages had impaired glucose tolerance or frank diabetes as compared with about $15 \%$ of patients without haemorrhages, this difference being statistically significant. Previous workers have measured blood sugar levels two hours after a meal ${ }^{4}$ or have measured fasting glucose levels or done glucose tolerance tests on a small number of patients ${ }^{10}$ without finding any differences between patients with and without haemorrhages. The fact that our study showed that a difference may be due to the application of rather more stringent tests of glucose metabolism to a fairly large number of patients. The second difference which we found (Fig. 1) was that disc haemorrhages were detected more often in patients with lower intraocular pressures (IOP). It is to be borne in mind that the IOPs recorded here were the maximum (and therefore untreated) values recorded during the routine observation period of the patients. This observation is comparable with the finding of other workers" that

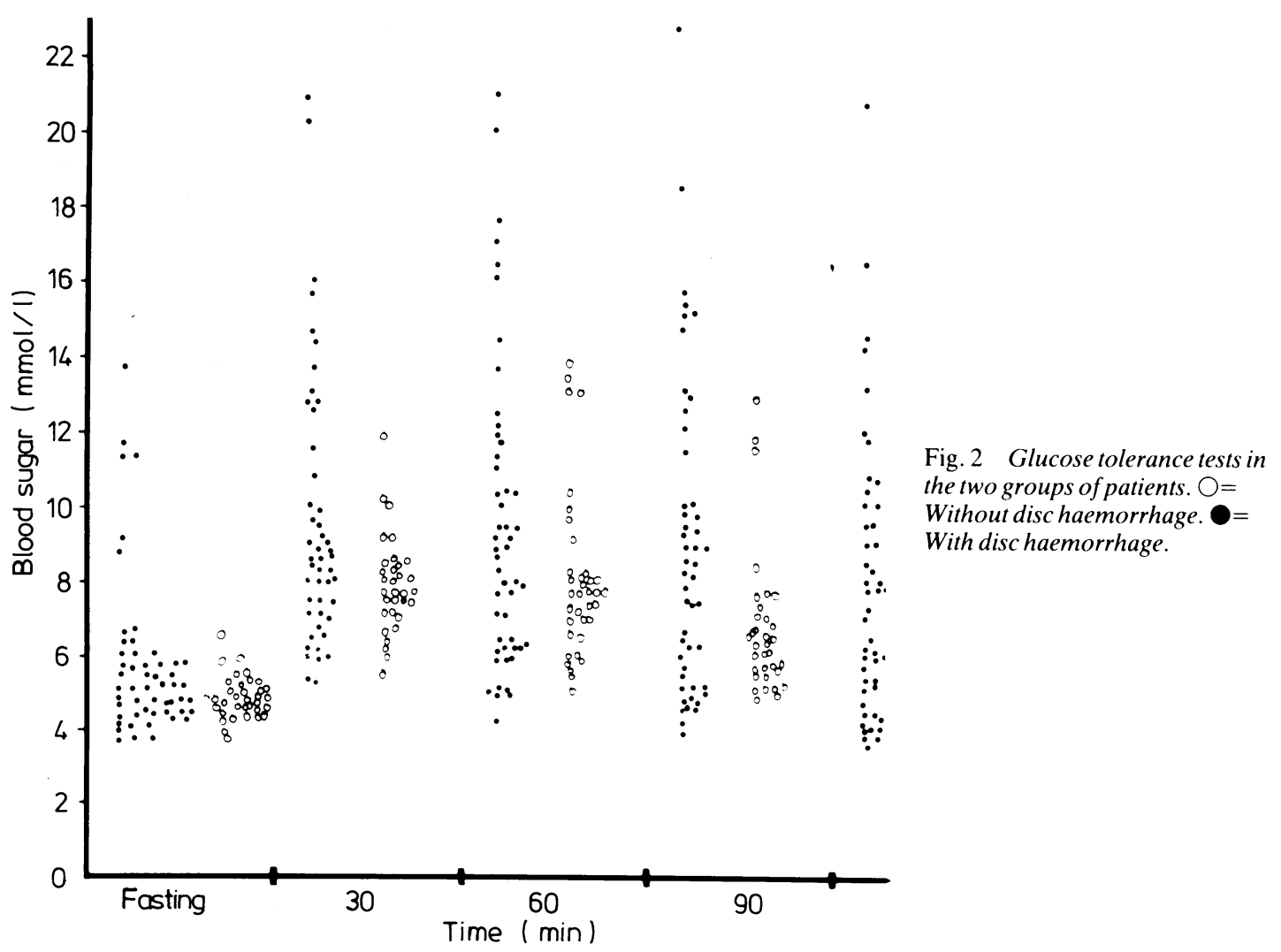




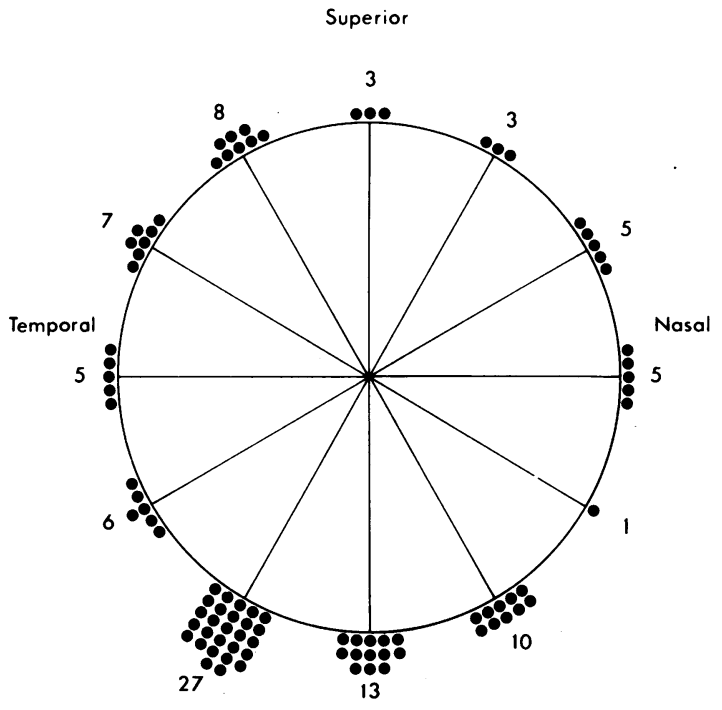

Inferior

Fig. 3 Distribution of haemorrhages in various sectors of the disc.

disc haemorrhages are relatively common in low tension glaucoma.

By contrast no conclusions could be drawn from our study regarding the possible influence of the level of systemic blood pressure on the occurrence of disc haemorrhages in glaucoma. On the one hand there was no significant difference in mean blood pressure between the two groups of patients, while on the other hand" there was a slightly higher incidence of systemic hypertension (defined as having diastolic pressure of $110 \mathrm{mmHg}$ or more) in the group with disc haemorrhages. Other workers" have found a significantly higher prevalence of systemic hypertension in glaucoma patients with disc haemorrhages as compared with those without. The unequal distribution of haemorrhages in the various sectors of the optic disc, already described by other authors ${ }^{12}$ was confirmed in this study together with the variation in levels of IOP associated with the occurrence of haemorrhages in the different sectors. These findings are probably explicable in terms of structural variations in the disc tissues from sector to sector. ${ }^{13 / 4}$

The association of disc haemorrhages in glaucoma with disordered glucose metabolism and with low intraocular pressure may be explained in several ways, but the results of this investigation do not favour any particular explanation. They do, however, make one point of direct clinical interest. This is that there is a possibility of coexisting diabetes mellitus in the glaucoma patient not only in cases of low tension glaucoma but also when disc haemorrhages are observed.

\section{References}

1 Becker B. Diabetes mellitus and primary open angle glaucoma. Ophthalmology (Rochester) 1971; 75: OP 239-59.

2 Bengtsson B, Holmin C, Krakau CET. Disc haemorrhage and glaucoma. Acta Ophthalmol (Kbh) 1981; 59: 1-14.

3 Drance SM, Begg IS. Sector haemorrhage-a probable acute ischaemic disc change in chronic simple glaucoma. Can $J$ Ophthalmol 1970; 5: 1237-41.

4 Susanna R, Drance SM, Douglas GR. Disc haemorrhages in patients with elevated intraocular pressure. Occurrence with and without field changes. Arch Ophthalmol 1979; 97: 284-5.

5 Gloster J. Incidence of optic disc haemorrhages in chronic simple glaucoma and ocular hypertension. Br J Ophthalmol 1981; 65: 452-6.

6 Airaksinen PJ, Mustonen E, Alanko HI. Optic disc haemorrhages precede retinal fibre layer defects in ocular hypertension. Acta Ophthalmol (Kbh) 1981; 59: 627-41.

7 Drance SM, Fairclough M, Butler MD, Kottler MS. The importance of disc haemorrhage in the prognosis of chronic open angle glaucoma. Arch Ophthalmol (Kbh) 1977; 95: 226-8.

8 World Health Organisation Expert Committee on Diabetes Mellitus. Second Report. WHO Tech Rep Ser 1980: 648.

9 Kottler MS, Drance SM. Studies of haemorrhage on the optic disc. Can J Ophthalmol 1976; 11: 102-5.

10 Begg IS, Drance SM, Sweeney VP. Ischaemic optic neuropathy in chronic simple glaucoma. Br J Ophthalmol 1971; 55: 73-90.

11 Drance SM, Sweeney VP, Morgan RW, Feldman F. Studies of factors involved in the production of low tension glaucoma. Arch Ophthalmol 1973; 89: 458-65.

12 Airaksinen PJ, Mustonen E, Alanko HI. Optic disc haemorrhages-analysis of stereophotographs and clinical data of 112 patients. Arch Ophthalmol 1981;99: 1795-1801.

13 Quigley HA, Addicks EM. Regional differences in the structure of the lamina cribrosa and their relation to glaucomatous optic nerve damage. Arch Ophthalmol 1981;99: 137-43.

14 Radius RL. Regional specificity in anatomy at the lamina cribrosa. Arch Ophthalmol 1981;99: 478-80.

Accepted for publication 4 December 1985. 